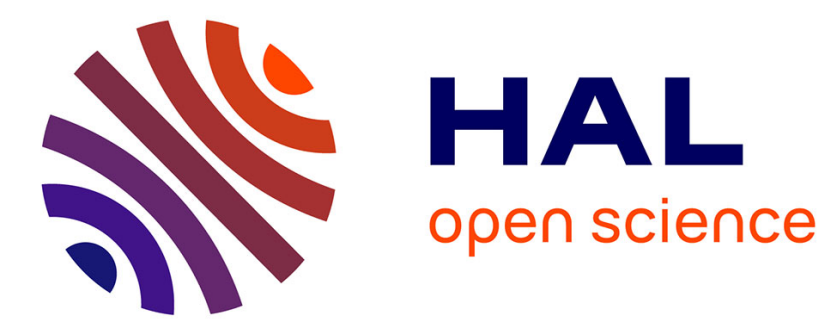

\title{
Un four gallo-romain à Labuissière (Pas-de-Calais)
}

Marie Tuffreau-Libre

\section{To cite this version:}

Marie Tuffreau-Libre. Un four gallo-romain à Labuissière (Pas-de-Calais). Gallia - Fouilles et monuments archéologiques en France métropolitaine, 1980, 38 (2), pp.291-309. 10.3406/galia.1980.1804 . hal-01936243

\section{HAL Id: hal-01936243 \\ https://hal.science/hal-01936243}

Submitted on 27 Feb 2020

HAL is a multi-disciplinary open access archive for the deposit and dissemination of scientific research documents, whether they are published or not. The documents may come from teaching and research institutions in France or abroad, or from public or private research centers.
L'archive ouverte pluridisciplinaire HAL, est destinée au dépôt et à la diffusion de documents scientifiques de niveau recherche, publiés ou non, émanant des établissements d'enseignement et de recherche français ou étrangers, des laboratoires publics ou privés.

\section{(이) $\$$}

Distributed under a Creative Commons Attribution - NonCommercial - NoDerivatives| 4.0 


\title{
UN FOUR GALLO-ROMAIN A LABUISSIÈRE (Pas-de-Calais)
}

\author{
par Marie TUFFREAU-LIBRE
}

Le site gallo-romain de Labuissière (Pas-deCalais) a été découvert en 1971 (fig. 1), à $6 \mathrm{~km}$ au s.-o. de Béthune en bordure de la route nationale 41 (fig. 2). L'implantation d'un hypermarché nécessita alors un important décapage $\left(35000 \mathrm{~m}^{2}\right)$, réalisé durant le mois d'octobre. Les travaux révélèrent des vestiges nombreux : au n.-o., des substructions galloromaines; au centre une voie large de $5 \mathrm{~m}$ en galets, à l'e. une importante aire de potiers (130 fours) avec des puits à eau, des dépotoirs, des sépultures ${ }^{1}$. Une fouille de sauvetage fut alors entreprise, à laquelle participèrent les Amis du Musée de Béthune, les membres de la future Société de Recherche historique de Bruay-Labuissière, et notamment F. Roger et A. Bourgeois ${ }^{2}$. Le sauvetage fut malheureusement très limité par rapport à l'importance du site et la majeure partie des renseignements qu'aurait pu fournir cette officine (productions par fours, renseignements statistiques sur les fournées, datations précises) est perdue. Les fouilles se poursuivirent sur le site dans les

1 F. Roger, L'officine atrébate de Labuissière, 1972,79 , p. 55, fig. Nous remercions vivement M. F. Roger, qui nous a autorisé à utiliser ce travail.

2 A. Bourgeors, L'oflcine de potiers de Labuissière, rapport préliminaire, dans Bull. Commis. départementale des Monuments historiques du Pas-de-Calais, IX, 1972, p. 102-116, 4 fig., 2 pl. h.-t. Nous remercions également M. A. Bourgeois qui a bien voulu nous communiquer des dessins de céramiques retrouvées lors de la campagne de 1971 . années qui suivirent, menées par G. Vion ${ }^{3}$ mettant au jour diverses structures.

En 1977, des travaux préliminaires à un lotissement, effectués sur la parcelle $\mathrm{n}^{0} 12$, section A.M., révélèrent les structures d'un four gallo-romain. Une fouille de sauvetage fut organisée, qui permit le dégagement d'un four à chambre de chauffe rectangulaire et fournit un mobilier assez important composé essentiellement de céramiques communes. L'ensemble était d'autant plus intéressant qu'il s'agissait du premier four fouillé entièrement depuis la destruction de 1971, si l'on excepte l'étonnant four "penté " découvert sans aucun mobilier4.

Le four dégagé a un laboratoire légèrement ovalaire. Il comporte au centre un support de sole en languette, détaché de la paroi, large de $0,24 \mathrm{~m}$ et long de $1 \mathrm{~m}$. La sole du four a complètement disparu. La chambre de chauffe est rectangulaire $[3,30 \mathrm{~m}$ de large, sur $2,70 \mathrm{~m}$ dans la plus grande longueur). Le fond du laboratoire est à $0,65 \mathrm{~m}$ de profondeur ; celui de la chambre de chauffe varie de $0,80 \mathrm{~m}$ à $0,90 \mathrm{~m}$. Le fond, les parois du conduit et du laboratoire sont fortement vitrifiés, sur une

3 G. Vion, Cinq ans de recherches archeologiques $\dot{a}$ Labuissière (1972-1977), dans Bull. Commis. départementale des Monuments historiques du Pas-de-Calais, X, 1978, p. 87-101, 7 fig. M. G. Vion, nous a aimablement communiqué des dessins des objets trouvés en 1971.

4 G. VIon, op. cit. 


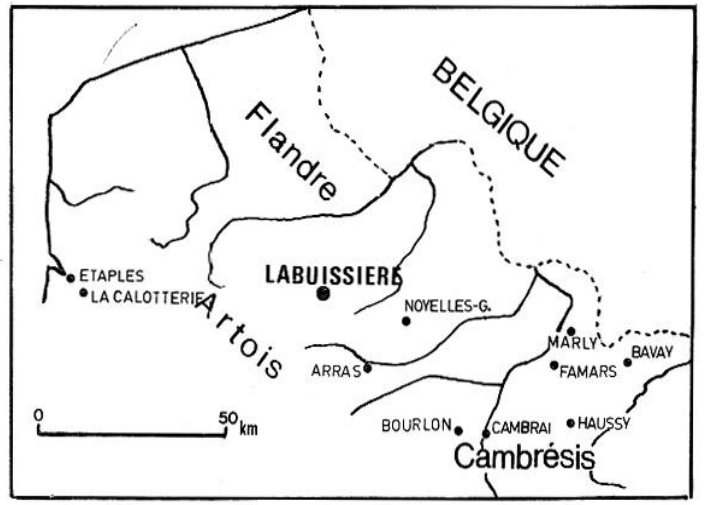

1 Situation de Labuissière dans le Nord de la France.

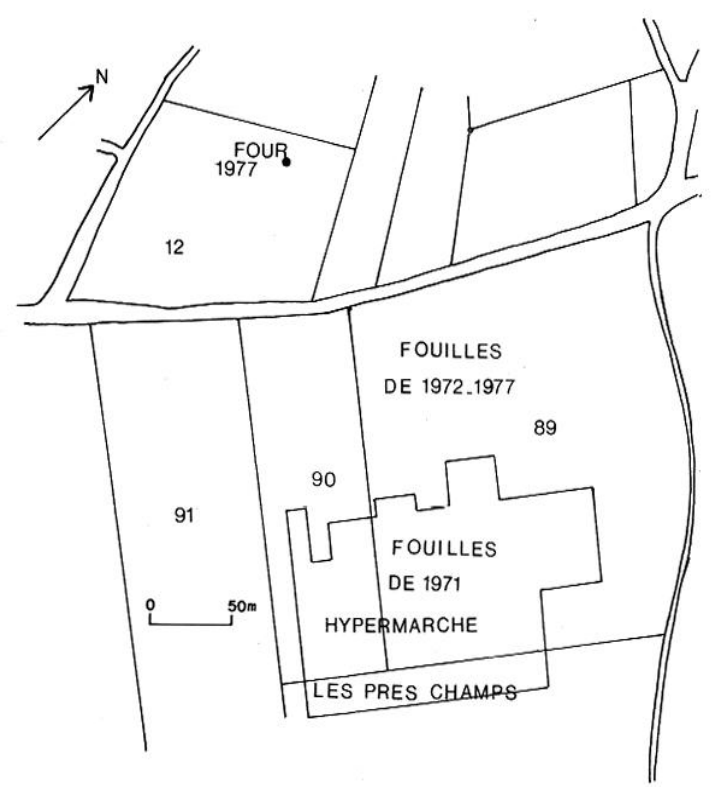

2 Plan du site de Labuissière ; fouilles de 1971 à 1977.

épaisseur allant jusqu'à $3 \mathrm{~cm}$. Le laboratoire était remblayé d'un mélange comprenant de nombreux débris de sole et de terre cuite. Il contenait peu de vestiges : quelques fragments de cruche et un vase tronconique écrasé sur place. Le remblai de la chambre de chauffe comprenait peu de débris du four mais un mobilier important composé de céramiques sigillées, de céramiques communes. Quelques fragments de verre, de bronze, une monnaie $\mathrm{du} \mathrm{I}^{\mathrm{er}} \mathrm{s}$. ont également été découverts (fig. 3).

Ce type de four avait déjà été reconnu lors des fouilles de 1971. En effet, les fours de
Labuissière appartiennent à des types divers : le four à sole perforée, à chambre de chauffe carrée ou rectangulaire, est bien représenté. Le support de sole est soit en languette, en pilier central soit en croix. Le four à plate-forme est également fréquent à Labuissière. Il comporte deux foyers et deux chaufferies. La sole perforée est remplacée par une plate-forme pourvue de rigoles. De forme ovalaire ou circulaire, elle possède une rigole périphérique ou des rigoles périphérique et centrale (fig. 4). Le four de 1977 appartient donc à la catégorie des fours à sole perforée, à support de sole en languette, très fréquent sur le site.

\section{Le mobilier trouvé à l'intérieur du laboraloire (fig. 5) :}

1 : vase tourné; col tronconique; panse carénée ; petit pied saillant ; fond légèrement concave; couleur grise; (Munsell Soil Color Charts : 10 YR 6/1,5/1); pâte grise, à dégraissant sableux, bien cuite. Le col est orné de bandes lissées horizontales et parallèles. Type IIa des vases tronconiques ${ }^{5}$, connu dans le nord de la France à Marly (première moitié du $\left.{ }_{I^{\mathrm{e}}}^{\mathrm{e}} \mathrm{s}.\right)^{6}$, à Noyelles-Godault (première moitié $\mathrm{du} \mathrm{1}^{\mathrm{er}}$ s. $)^{7}$, à La Calotterie ( $\left(\mathrm{II}^{\mathrm{e}} \mathrm{S} \text {., début du III }{ }^{\mathrm{e}} \mathrm{s} .\right)^{8}$, à Arras ${ }^{9}$, Haussy (milieu du I ${ }^{\text {er }}$ s. au milieu $\mathrm{du}$ II $\left.^{\mathrm{e}} \mathrm{s}.\right)^{10}$, à Graincourt-lès-Havrincourt

5 Tuffreau-Libre, La céramique commune galloromaine dans le Nord de la France (Nord el Pas-deCalais), thèse de $3^{\mathrm{e}}$ cycle, Université de Lille III, 1976, 216 p., 95 fig.

6 M. TufFreau-Libre, Un dépotoir gallo-romain du II ${ }^{\text {e }}$ siècle à Marly (Nord), dans Gallia, 36, 1978, p. 163-186, 12 fig.

7 J.-M. Bastien et P. Demolon, Villa et cimetière du $I^{\mathrm{er}}$ siècle après J.-C. à Noyelles-Godaull (Pas-deCalais), dans Septentrion, 5, 1975, 35 p., 23 fig.

8 J. Couppé, M. Tuffreau-Libre et F. Vincent, L'officine gallo-romaine de La Calollerie, dans Revue du Nord, 1977, LIX, p. 501-544, 22 fig.

9 M. Tuffreau-Libres, La céramique commune gallo-romaine du sile de Baudimont $\dot{a}$ Arras, dans Bull. Commis. départementale des Monuments historiques du Pas-de-Calais, X, 1978, p. 178-205, 16 fig.

10 M. Tuffreau-Libre et. P. Turouin, La céramique commune gallv-romaine de Haussy (Nord), dans Revue du Nord, LVIII, 1976, p. 609-621, 7 fig. 

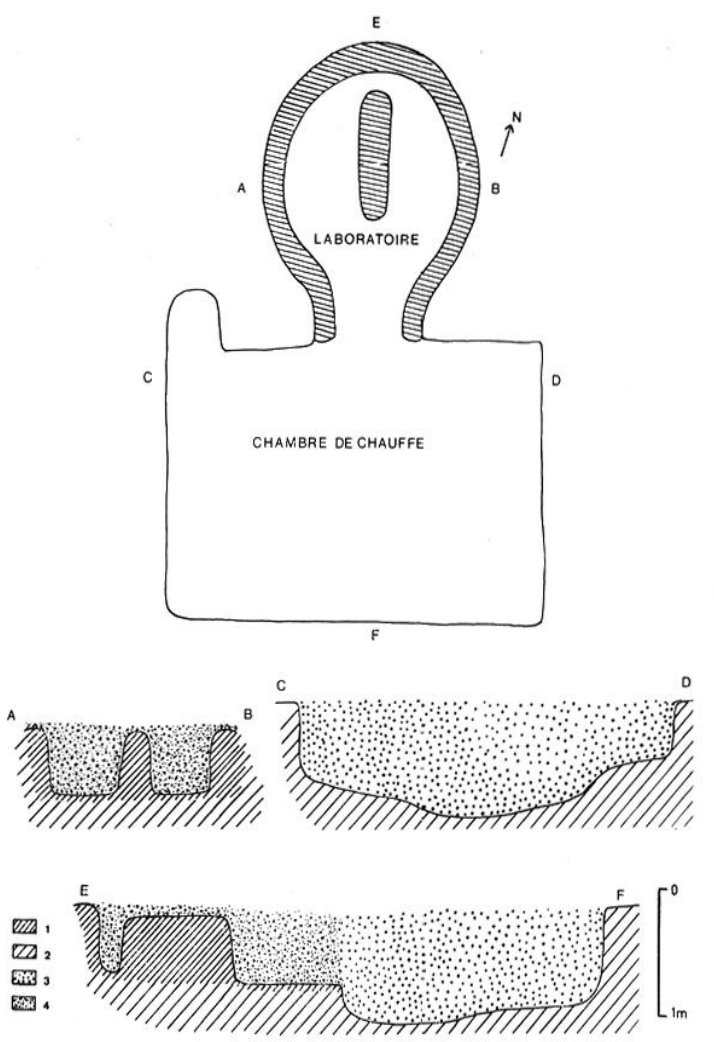

$\left(\mathrm{IV}^{\mathrm{e}} \mathrm{s} .\right)^{11}, \dot{a}$ Eswars ${ }^{12}$. En fait on rencontre ce type de vase sur presque tous les sites gallo-romains du nord de la France ayant des datations allant de la fin du $\mathrm{I}^{\mathrm{er}} \mathrm{s}$. au IV ${ }^{\text {e }}$. Il est plus rare sur les sites plus anciens. Il existe également en Picardie à Amiens ${ }^{13}$, en Belgique à Howardries ${ }^{14}$,

11 B. Machut el M. Tuffreau-Libre, La cave gallo-romaine de Graincourt-les-Havrincourt, dans Quadrivium, à parâitre.

12 A. VANDERSCHELDEN, Le cambrésis gallo-romain. Nouvel etat des recherches, dans Revue du Nord, LVI, 1974 , p. 533-568, 21 fig.

13 Collections du musée d'Amiens.

14 M. $\Lambda$ Mand, L'industric de la cćramique dans le sile du bois de Flines, à Howardries, dans Archaeologia Belgica, 127, 1971, 75 p., 30 fig.

3 Plan el coupes du four ; 1 : argile cuite ; 2 : limon argileux ; 3 : remblai ; 4 : remblai contenant de nom$\leftarrow \quad$ breux débris de sole et de terre cuite.
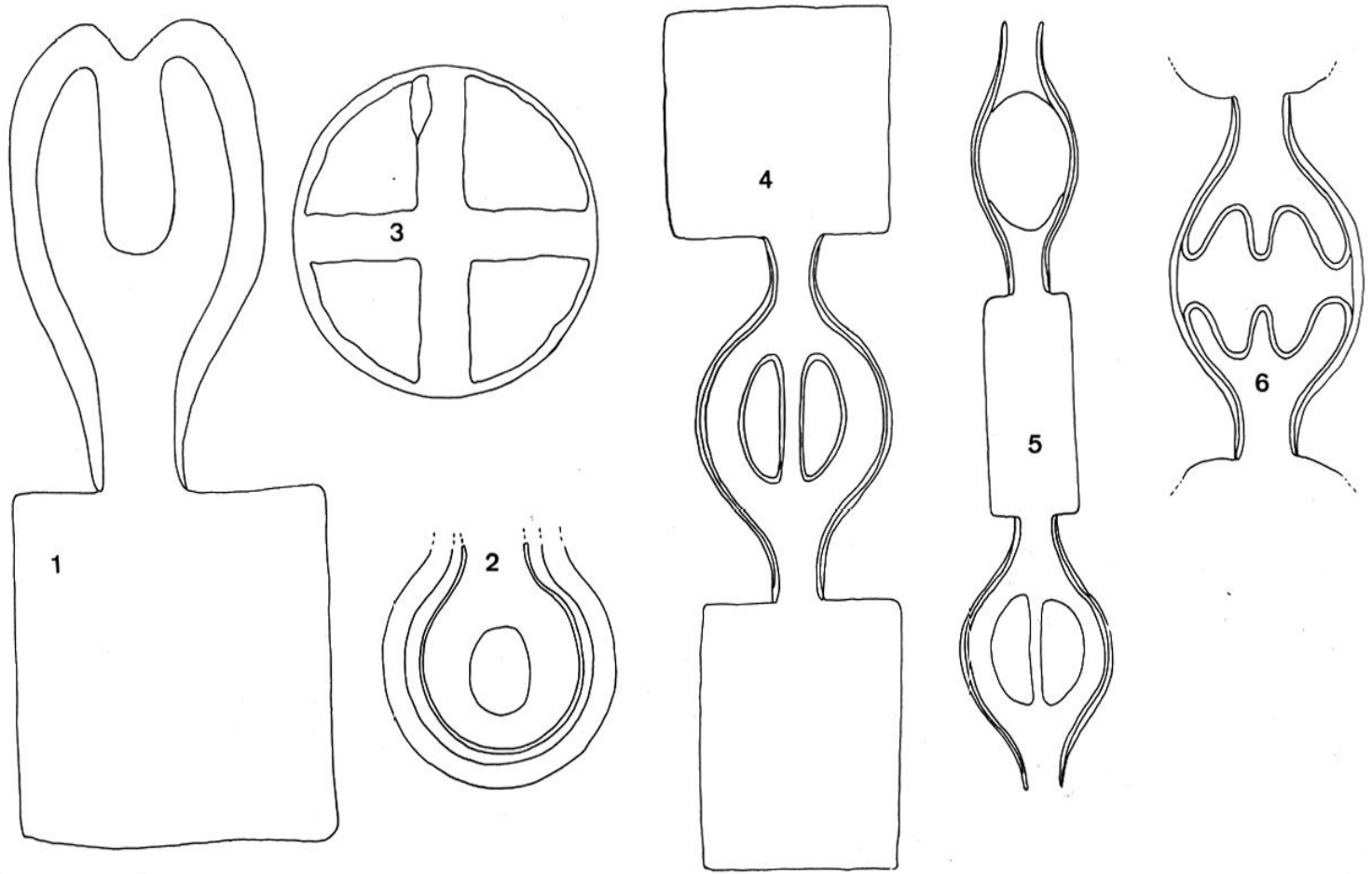

4 Différents types de fours connus à Labuissière; 1 à 3 : fours à sole perforée ; 4 à 6 : fours à plate-forme (d'après F. Roger). 
Robechies $^{15}$, Werwik ${ }^{16}$, Destelbergen ${ }^{17}$, Blicquy ${ }^{\mathbf{1 8}}$;

2 : cruche tournée; lèvre épaisse, arrondie ; col légèrement concave, marqué d'un renflement aigu dans la partie supérieure ; panse évasée; anse aplatie bombée légèrement, s'attachant sous la lèvre ; couleur grise (5 YR 4/1); traces de peinture blanche; pâte orange à dégraissant sableux, bien cuite.

Le mobilier trouvé à l'intérieur de la chambre de chauffe (fig. 5 à 9 ) :

La céramique sigillée,

3 : assiette Drag. 18/31; couleur rouge (10 $\mathrm{R} 5 / 6)^{19}$;

4: assiette Drag. 18/31: couleur rouge (2,5 YR 4/8) ;

4 : assiette Drag. $18 / 31$; couleur rouge (10 $\mathrm{R} 5 / 6)$;

6 : tasse Drag. 33 ; couleur rouge (10 R 4/8);

7 : bol Drag. 37 ; couleur rouge (10 R 5/8); décor d'oves suivi d'un cordon perlé.

La céramique commune : les assiettes,

8 : assiette tournée; lèvre arrondie; panse ronde; couleur grise (5 YR 4/1); pâte grise, à dégraissant sableux, bien cuite. Type Ia des assiettes à panse ronde, connu dans le Pas-de-Calais à Étaples ${ }^{20}$, dans le Nord à Lewarde ${ }^{21}$, à Marly (première

15 P. Spitaels, La nécropole gallo-romaine de Robechies, près de Chimay, dans L'Antiquité classique, XXVI, 1957, p. 91-146, 37 fig.

$16 \mathrm{H}$. GoEmine, Opgravingen in de romeinse Vicus te Wervik, dans Archaeologia Belgica, 117, 1970, 74 p., 21 fig.

17 S. J. de Laet, H. Thoen et A. van Doorselaer, La tombe collective de Destelbergen-lez-Gand, dans Helinium, X, 1970, p. 3-30, 32 fig.

18 S. J. De Laet, A. van Doorselaer, P. Spitaels et $\mathrm{H}$. Тнове, La nécropole gallo-romaine de Blicquy (Hainaut, Belgique), dans Dissertationes Archaeologicae Gandenses, 1972, 159 p., 152 fig.

19 F. Oswald et T. D. Pryce, An introduction to the study of terra sigillata, Londres, 1920.

20 M. Tuffreau-Libre, Recherches sur les fouilles gallo-romaines d'Etaples (Pas-de-Calais), mémoire de maîtrise, Université de Lille III, 1974, 128 p., 35 fig.

21 P. Demolon, M. Tuffreau-Libre et A. Vadet, Le site gallo-romain des lerres Noires à Lewarde (Nord), dans Revue du Nord, à paraître. moitié du II ${ }^{\mathrm{e}}$ s.). Il existe en Picardie à Champlieu ${ }^{22}$, ainsi qu'à Saint-Ulrich (Moselle) ${ }^{23}$, à Pépiron (Charente-Maritime) ${ }^{24}$, en Belgique a Tongres (type 210, $\mathrm{I}^{\mathrm{e}} \mathrm{s}$. ) $^{25}$, aux Pays-Bas à Nimègue ${ }^{26}$, en Rhénanie (type Gose 230, II ${ }^{\mathrm{e}}$ s.) ${ }^{27}$, à Straubing $\left(\mathrm{II}^{\mathrm{e}} \mathrm{s} .\right)^{28}$, en Angleterre à Verulamium ${ }^{29}$ :

9 : assiette tournée; lèvre arrondie; panse ronde; couleur grise (5 YR 4/1); pâte grise, à dégraissant sableux, bien cuite. Type Ia des assiettes à panse ronde;

10 : assiette tournée; lèvre anguleuse; partie supérieure oblique; panse carénée ; couleur brun clair (10 YR 5/1); pâte brune, à dégraissant sableux, bien cuite. Type IIa des assiettes à panse carénée, connu dans le Pas-de-Calais à Arras, NoyellesGodault, dans le Nord à Famars ${ }^{30}$, Lewarde (II $\mathrm{s}$. ) ;

11 : assiette tournée à enduit rouge pompéien ; panse oblique; pied oblique; couleur intérieure rouge (7,5 YR 8/4); pâte grise à dégraissant sableux, bien cuite. Type IIIa des assiettes à panse oblique, très répandu dans le nord de la France, connu à Maubeuge, Haussy, Arras, Lewarde,

22 M. Tuffreau-Libre, La céramique commune gallo-romaine de la forêt de Compiègne (Oise) au Musée des Antiquités nationales, dans Cahiers archéologiques de Picardie, 4, 1977, p. 125-150, 10 fig.

23 M. Lutz, Le domaine gallo-romain de SaintUlrich (Moselle) (I), dans Gallia, XXIX, 1971, p. 17-44, 19 fig.

24 G. GABET, La céramique gallo-romaine recueillie à Pépiron (Charente-Marilime), dans Gallia, XXVII, 1969 , p. $45-7$ I, 32 fig.

25 W. VANVINCKEnRoYEW, Gallo-romeins aardewek van Tongeren, Tongres, 1967, 69 p., 26 pl. h.-t.

26 P. STUART, Gewoon aardewek uit de romeinse legerplaats en de bijbehorende grafvelden te Nijmegen, dans Oudheidkundige Mededelingen, XLIII, 1962, 176 p., 29 pl. h.-t.

27 E. Gose, Gefässtypen der romischen Keramik im Rheinland, Rheinishes Landesmuseum, 1950, 47 p., 61 pl. h.-t.

28 N. Walke, Das romische Donaukastell StraubingSorviodurum, dans Limesforschungen Band, 3, 1965, 176 p., 18 fig., 152 pl. h.-t.

29 S. Frere, Verulamium excavations, dans Reporis of the Research Committee of the Society of Antiquaries of London, XXVIII, 1972, 381 p., 146 fig., 60 pl. h.-t.

30 Ph. Beaussart, L'exploration archéologique de Famars: les données du Haut-Empire, dans Revue du Nord, LVIII, 1976, p. 621-673, 18 fig. 

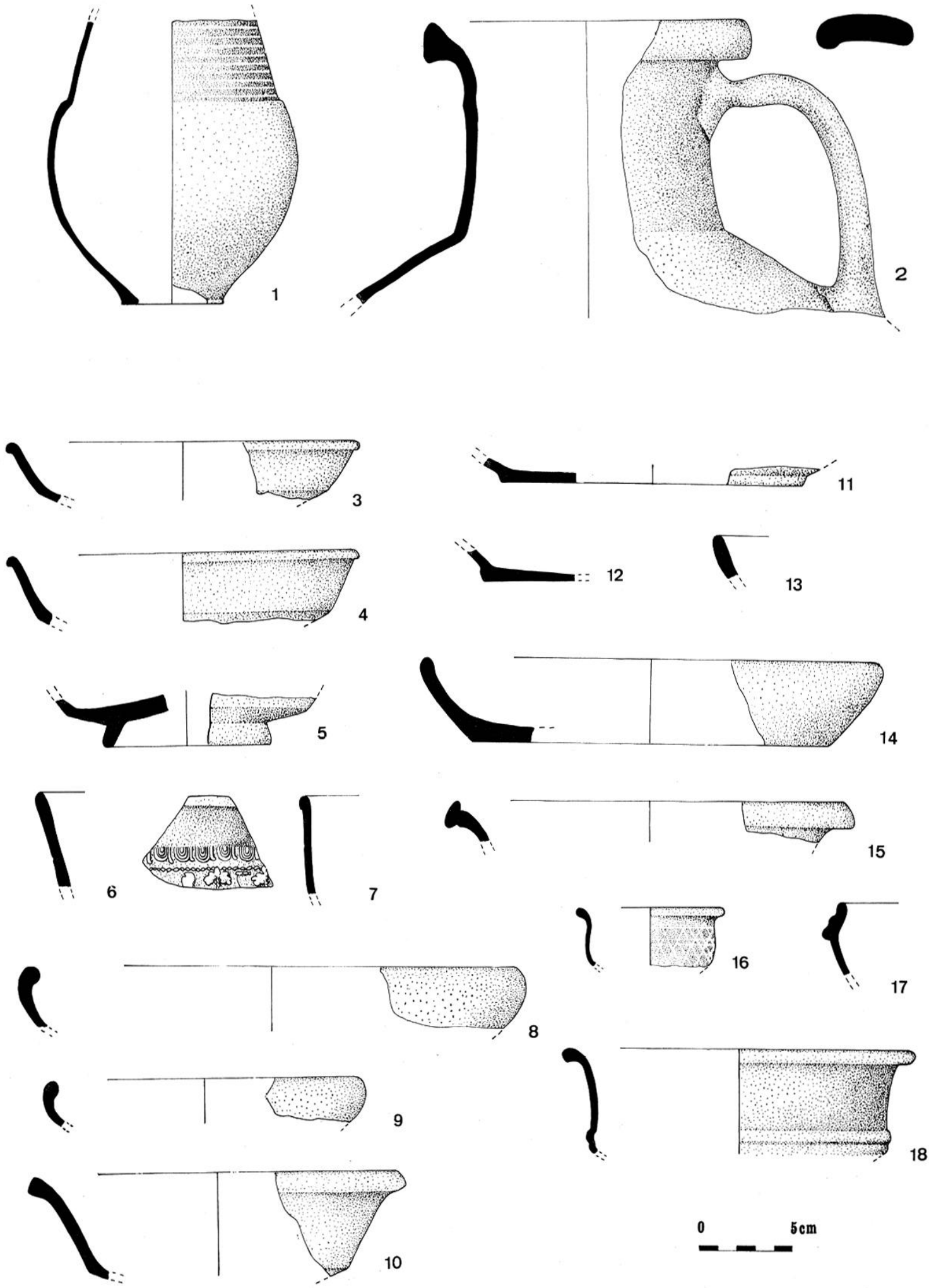

5 Mobilier du four; céramiques sigillées et céramiques communes. 
Graincourt-lès-Havrincourt, La Calotterie, Etaples, Thérouanne ${ }^{31}$. Il s'agit du type V de Blicquy (début du ${ }_{i}{ }^{\mathrm{e}} \mathrm{s}$. au début du $\mathrm{III}^{\mathrm{e}} \mathrm{s}$.) ${ }^{32}$. Il est également connu en Picardie à La Carrière du Roi, en forêt de Compiègne $\left(\mathrm{r}^{\mathrm{e}} \mathrm{s} .\right)^{33}$, à Mercin et $\operatorname{Vaux}^{34}$;

12 : assiette tournée à enduit rouge pompéien ; panse oblique; pied oblique ; fond plat; couleur intérieure rouge (10 R 5/6); extérieur beige; pâte beige, à dégraissant sableux, bien cuite. Type IIIa des assiettes à panse oblique ;

13 : assiette tournée à enduit rouge pompéien ; lèvre arrondie; panse oblique; couleur rouge (10 R $5 / 6)$; pâte beige à dégraissant sableux, bicn cuite;

14 : assiette tournée; lèvre arrondie; panse oblique ; fond plat ; couleur orange $(7,5$ YR 6/6); pâte orange, à dégraissant fait de gravier pilé, bien cuite. Type IVa des assiettes à panse oblique, connu à NoyellesGodault (Auguste-Claude), à Famars (Ir ${ }^{\mathrm{e}}$ s.). Il existe en Rhénanie à Straubing (fin du $\mathrm{I}^{\mathrm{er}}$ au milieu du II $^{\mathrm{e}} \mathrm{s}$.), en Angleterre à Verulamium (type 527, 105-130 ap. J.-C.), à Colchester (type 40A, 100-400 ap. J.-C. $)^{35}$ à Ospringe (type 384$)^{36}$;

15: assiette tournée en terra nigra; lèvre oblique, arrondie; saillant dans sa partie interne; partie supérieure concave ; couleur noire (2,5 YR N 2,5/) ; pâte gris clair, bien cuite. Type Ia des assiettes à panse anguleuse, connu ̀̀ Noyelles-Godault

31 R. Delmaire, Étude archéologique de la partie orientale de la Givitas Morinorum, thèse de $3^{\mathrm{e}}$ cycle, Lille, 1972, 3 vol., 427 p., 61 fig., 3 pl. h.-t.

32 S. J. De LAet et $\mathrm{H}$. Thoen, La céramique à enduit rouge pompéien, dans Helinium, IX, 1969, p. 28-38, 20 fig.

33 J.-M. Frémont et B. Wormant, Le vicus galloromain de la Carrière du Roi en forêt de Compiègne (Oise), dans Revue archeologique de l'Oise, 6, 1975, p. 45-56, 7 fig.

34 A. Barbet et M. Tuffreau-Libre, à paraître.

35 M. R. Hull, Roman Colchester, dans Reports of the Research Committee of the Society of Antiquaries of London, XX, 1958, 301 p., 183 fig., 41 pl. h.-t.

36 W. Whiting, W. Hawley, T. May, Reports of the Excavations of the roman cimetery at Ospringe, Kent, dans Reports of the Research Committee of the Society of Antiquaries of London, VIII, 1931, 107 p., 64 fig.
(Auguste-Tibère), aux Pays-Bas à Nimègue (type 988), en Belgique à Tongres (type 49, (Auguste-Néron), à Sampont ${ }^{37}$, en Rhénanie (Gose type 296, Tibère-Claude).

Les bols,

16 : bol tourné; lèvre fine, arrondie; panse ronde; couleur gris clair (10 YR 5/1); pâte grise, à dégraissant sableux, bien cuite. La panse est ornée de bandes lissées entrecroisées ;

17 : bol tourné; lèvre moulurée ; panse oblique ; couleur grise (10 YR 5/1); pâte grise à dégraissant sableux, bien cuite. Type proche de ceux connus dans le nord à Marly (première moitié du ir $\mathrm{e}^{\mathrm{e}} \mathrm{s}$ ), à Haussy (milieu du ${ }^{\text {er }}$ s. au milieu du ${ }_{I^{e}}{ }^{e}$ s.), en Belgique à Tongres $\left(\mathrm{H}^{\mathrm{e}} \mathrm{s}\right.$.) et à Fin de Ville $\left(\text { fin }{ }_{\mathrm{II}^{\mathrm{e}}}^{\mathrm{e}} \text { début } \mathrm{III}^{\mathrm{e}} \mathrm{s} \text {. }\right)^{38}$, à Straubing $\left(\mathrm{I}^{\mathrm{er}}\right.$, II $^{\mathrm{e}}$ s.), à Blicquy ;

18 : bol caréné ; lèvre légèrement recourbée ; col concave; panse carénée, moulurée; couleur grise (10 YR $6 / 1,5 / 1)$; pâte grise à dégraissant sableux, bien cuite. Type XIVa des bols carénés, connu à Marly, Lewarde, Famars, La Calotterie, Labuissière. Il existe en Angleterre à Richborough (type 216);

19 : bol tourné; lèvre épaisse, s'affinant à l'extrémité ; col bombé, panse carénée; fond concave; couleur grise (10 YR 4/1); pâte grise à dégraissant sableux, bien cuite. Le col est orné de bandes lissées entrecroisées ;

20 : bol tourné ; lèvre épaisse, arrondie, anguleuse à l'extrémité ; col concave; panse carénée; pied oblique, légèrement marqué ; fond concave ; couleur grise (10 YR 4/1); pâte grise à dégraissant sableux, bien cuite. Le col et le haut de la panse sont ornés de bandes lissées parallèles. Type XVIa des bols carénés, connu à La Calotterie (II ${ }^{\mathrm{e}}$ s., début du $\mathrm{III}^{\mathrm{e}} \mathrm{s}$.), à Marly

37 J. NoËL, La nécropole gallo-romaine de Hunenknepehen $\dot{a}$ Sampont, dans Archaeologia Belgica, 106, 1968, 123 p., 71 fig., II pl. h.-t.

38 M. Meunier, La villa belgo-romaine de "Fin de ville" (commune de Mont-les-Houffalize), dans Archaeologia Belgica, 78, 1964, p. 154-172, 8 fig., 6 pl. h.-t. 

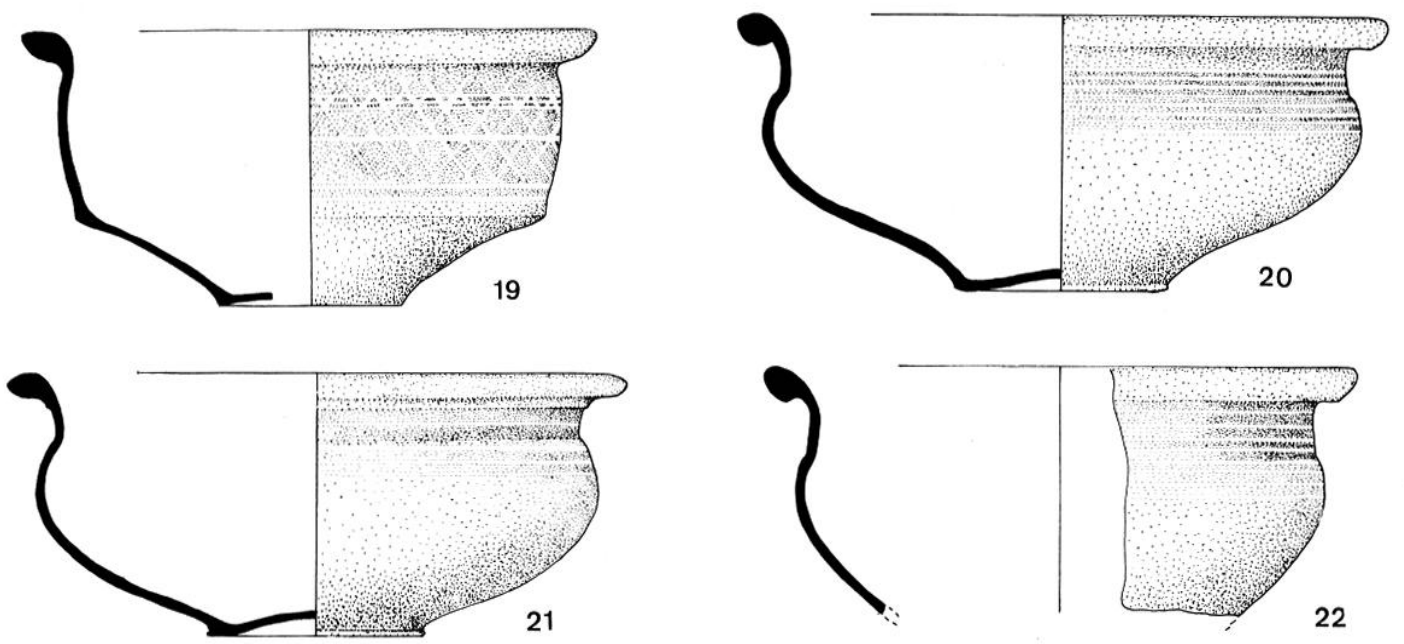

3

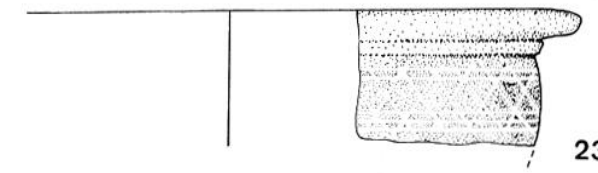

23
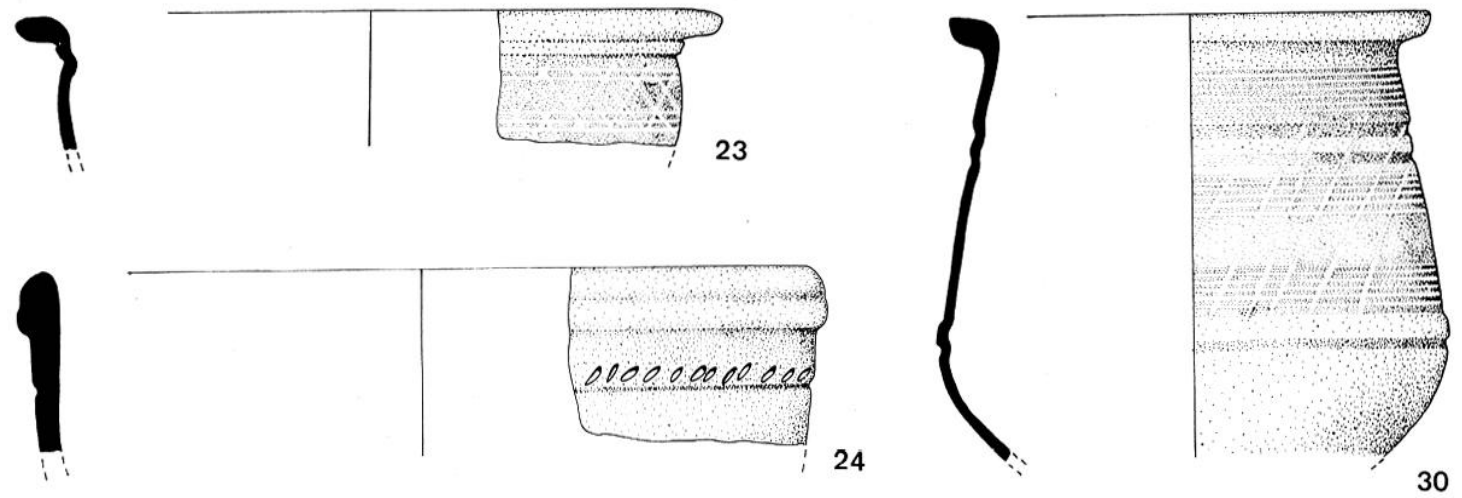
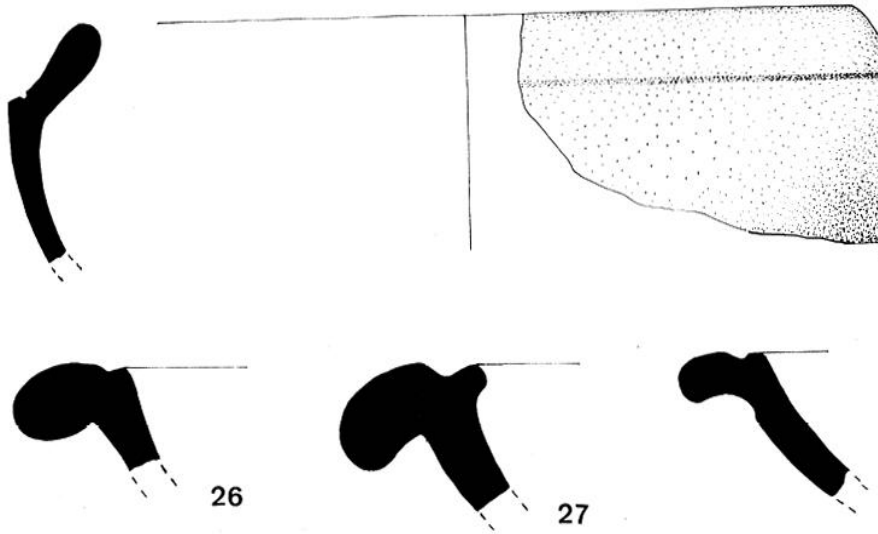

27
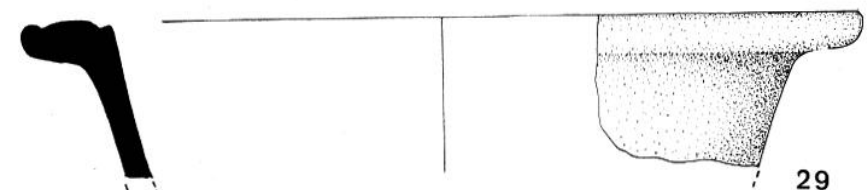

0

6 Mobilier du four; céramiques communes. 
(première moitié du $\mathrm{II}^{\mathrm{e}} \mathrm{s}$. ), à Lewarde ( I $^{\mathrm{e}}$ s.), à Maubeuge ${ }^{39}$, Haussy (milieu du I $^{\text {er }}$ s. au milieu du II $^{\mathrm{e}}$ s.), en Belgique à Blicquy ;

21 : bol tourné; lèvre allongée, s'affinant à l'extrémité, se terminant en corniche ; col concave ; panse carénée ; petit pied saillant, arrondi ; fond creusé ; couleur gris clair (7,5 YR N6/); pâte grise, à dégraissant sableux, bien cuite. Le col et le haut de la panse sont ornés de bandes lissées horizontales et parallèles. Type XVIa des bols carénés ;

22 : bol tourné ; lèvre épaisse, anguleuse à la base; col tronconique; panse carénée; couleur grise (10 YR 5/1); pâte grise, à dégraissant sableux, bien cuite. Le col et le haut de la panse sont ornés de bandes lissées parallèles. Type XVIa des bols carénés ;

23 : bol tourné; lèvre allongée, suivie d'une moulure; col bombé; couleur gris clair (10 YR 5/1) ; pâte gris clair, à dégraissant sableux, bien cuite. Le col est orné de bandes lissées horizontales et entrecroisées. Ce décor est également connu sur bol à Famars ;

24 : bol tourné ; lèvre épaisse, à une cannelure ; partie supérieure droite, moulurée; couleur orange (7,5 YR 6/4); pâte orange, à dégraissant sableux, bien cuite. Le col est orné d'incisions ovales irrégulières. Type connu à Bourlon (fin I ${ }^{\mathrm{er}}$, début du $\mathrm{II}^{\mathrm{e}} \mathrm{s}$. $)^{40}$;

25 : bol tourné ; lèvre épaisse, arrondie, prolongée par un col légèrement concave se terminant par un renfoncement; panse carénée ; couleur orange (5 YR 7/6); pâte orange à dégraissant fait de gravier pilé, bien cuite. Type VIIIa des bols carénés, connu à Lewarde, à Labuissière. Il existe en Belgique à Courtrai ${ }^{41}$.

$39 \mathrm{Ph}$. Hemmer, La céramique commune de la villa gallo-romaine du Bois-Brûlé (59, Maubeuge): essai de classification, dans Septentrion, 5, 1975, p. 45-60, 5 fig.

40 M. Tufrreau-Libre, La céramique de l'officine gallo-romaine du Pontrouge à Bourlon, dans Bull. Commis. déparlementale des Monuments historiques du Pas-de-Calais, X, 1976, p. 1-21, 14 fig.

41 Ch. Leva et G. Coene, Het gallo-romeins Grafueld in de Molenstraat te Korlrijk, dans Archaeologia Belgica, 114, 1969, 95 p., 38 fig., 5 pl. h.-t.
Les mortiers,

26 : mortier lourné ; lèvre épaisse, arrondie, oblique; panse oblique; couleur blanche (10 YR 8/3) ; pâte blanche à dégraissant sableux, bien cuite ;

27 : mortier tourné ; lèvre épaisse, pendante ; panse oblique ; couleur blanche $(7,5$ YR $8 / 2)$; pâte rougeâtre, à dégraissant sableux, bien cuite. Type connu à Pont-surSambre (première moitié du $\mathrm{II}^{\mathrm{e}} \mathrm{s}$. ) $^{42}$;

28 : mortier tourné; lèvre épaisse, allongée panse oblique ; couleur orange (5 YR 6/8); pâte orange à dégraissant fait de gravier pilé, bien cuite.

Les marmites,

29 : marmite tournée ; lèvre allongée, aplatie, moulurée; panse oblique ; couleur orange (5 YR 7/6); pâte orange à dégraissant sableux, bien cuite. Type Ia des marmites à panse oblique, connu à Bourlon (fin du I $^{\text {er }}$ s., début du II $^{\mathrm{e}} \mathrm{s}$.) et en forêt de Compiègne ;

30 : marmite tournée ; lèvre allongée, aplatie ; panse aplatie, moulurée; couleur gris jaunâtre (10 YR 6/1, 6/2); pâte grise à dégraissant sableux, bien cuite. La panse est ornée de bandes lissées parallèles et obliques très effacées. Type IIa des marmites à panse aplatie, très répandu dans le nord de la France, connu à Marly (première moitié du II $\mathrm{e}^{\mathrm{e}} \mathrm{s}$.), déjà connu à Labuissière. Il existe en Belgique à Blicquy et à Howardries ;

31 : marmite tournée; lèvre longue, aplatie; panse aplatie, moulurée; couleur grise (10 YR 5/2); pâte grise, à dégraissant sableux, bien cuite. La panse est ornée de bandes lissées parallèles et obliques, très effacées. Type IIa des marmites à panse aplatie ;

32 : marmite tournée ; lèvre allongée, aplatie arrondie à l'extrémité; panse aplatie, moulurée; couleur grise (7,5 YR N 4/); pâte grise à dégraissant sableux, bien cuite.

42 R. Delmaire, Les mortiers de Pont-sur-Sambre et l'atelier de Brariatius. Contribution à l'étude de la céramique bavaisienne, dans Septentrion, 2, 1972, p. 46-54, 6 fig. 

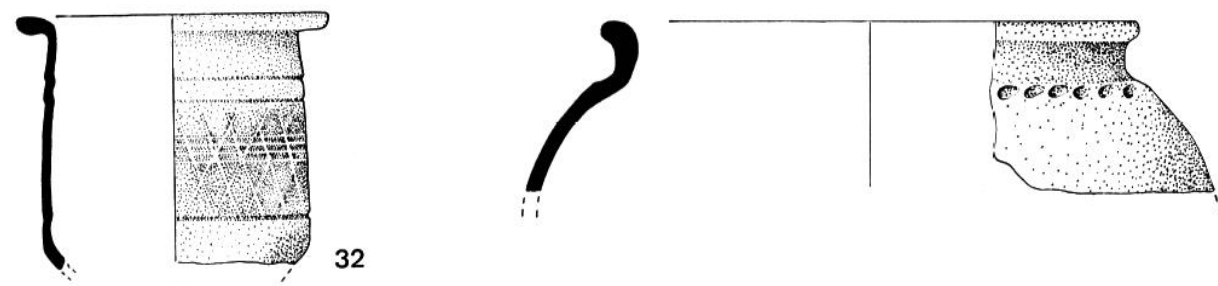

33
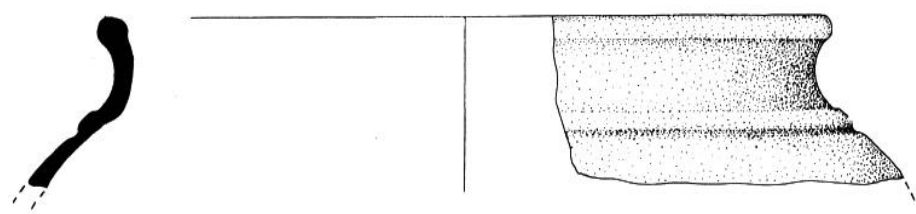

34
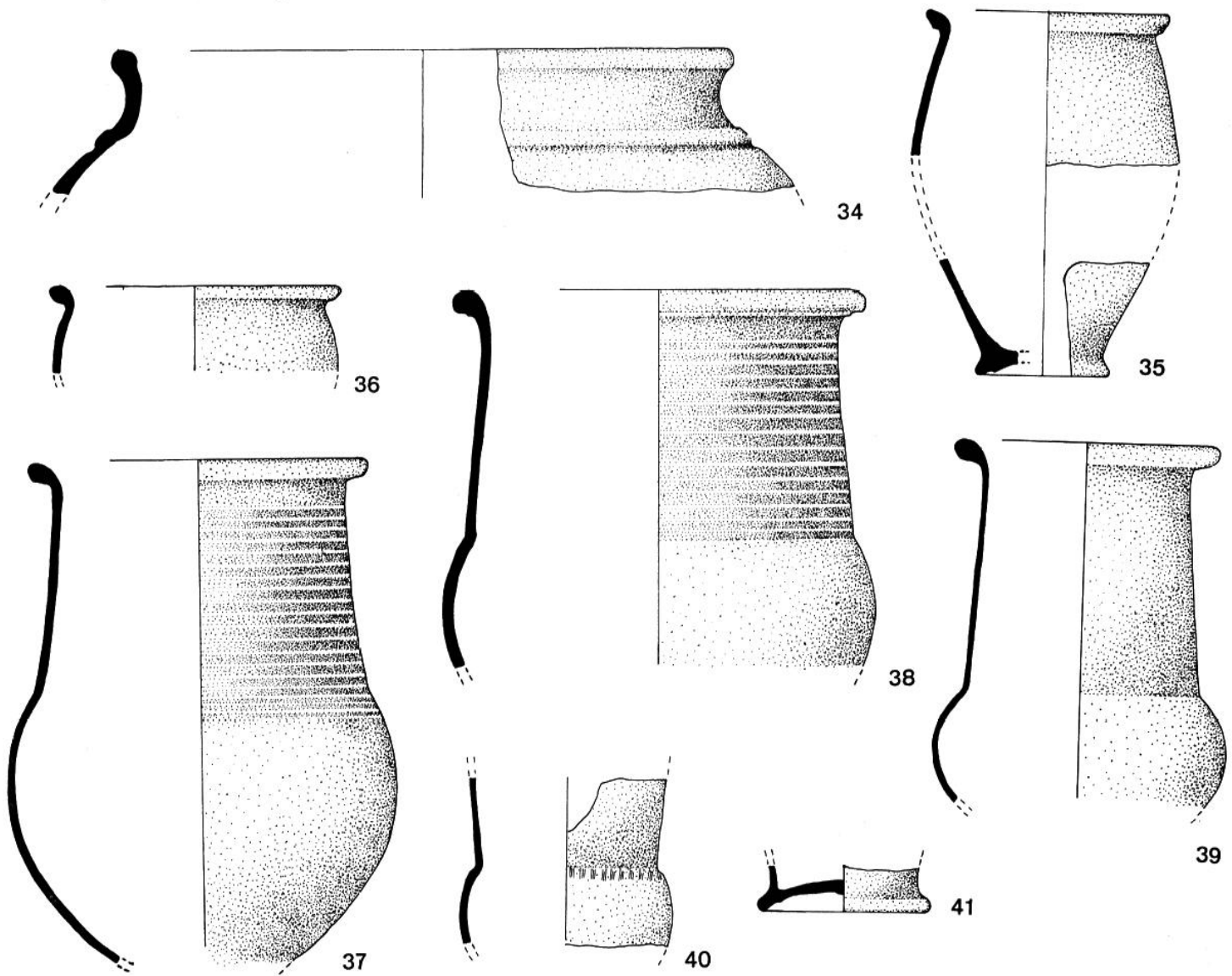

39
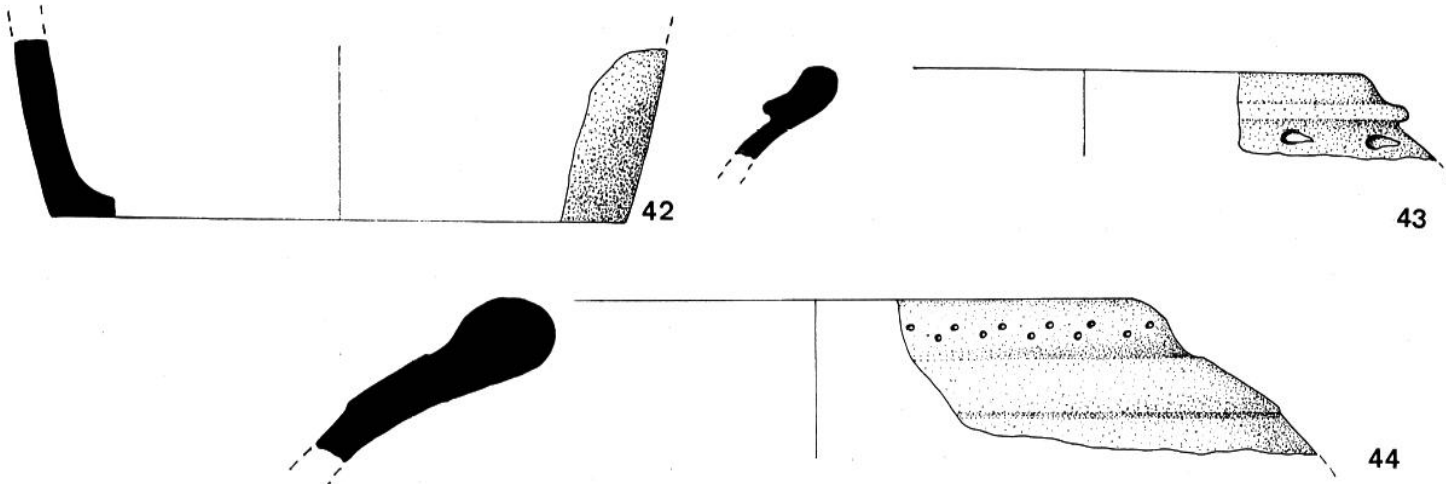

7 Mobilier du four; céramiques communes. 
La panse est ornée de bandes lissées entrecroisées très effacées. Type IIa des marmites à panse aplatie.

Les vases,

33 : vase tourné ; lèvre épaisse, arrondie ; court col concave; panse ronde; couleur grise (7,5 YR N 4/); pâte grise, à dégraissant sableux. Le haut de la panse est orné d'incisions grossièrement ovalaires. Type VIa des vases à panse ronde, connu dans le Pas-de-Calais à Noyelles-Godault (cimetière et vicus) (Auguste Tibère), en Belgique à Tournai ${ }^{43}$, ̀̀ Howardries, en Angleterre à Brought-on-Humber (période de Claude et Néron) ${ }^{44}$;

34 : vase tourné; lèvre épaisse, saillant vers l'intérieur ; col concave, suivi d'une moulure; panse ronde; couleur grise $(5 \mathrm{YR}$ $6 / 6)$; pâte grise à dégraissant sableux, bien cuite;

35 : vase tourné; lèvre oblique, légèrement concave; panse ovoïde; pied oblique; fond concave, marqué d'un anneau saillant; couleur gris clair (10 YR 6/1); pâte gris clair, très triable, à dégraissant sableux, bien cuite. La pâte diffère absolument de celles des autres céramiques;

36 : vase tourné ; lèvre s'affinant à l'extrémité ; panse aplatie; couleur gris clair (10 YR $5 / 1)$; pâte grise à dégraissant sableux, bien cuite ;

37 : vase tourné ; lèvre arrondie, allongée ; col tronconique; panse ronde; couleur brun jaunâtre (10 YR 6/3); pâte brune à dégraissant sableux, bien cuite. Le col et le haut de la panse sont ornés de bandes lissées parallèles. Type IIa des vases tronconiques ;

38 : vase tourné ; lèvre arrondie, se terminant par une petite corniche ; col tronconique ; panse ronde ; couleur brun jaunâtre (10 YR $5 / 3)$; pâte brune à dégraissant sableux,

43 M. Amand, Les vérilables origines de Tournai, dans Helinium, III, 1963, p. 193-204, 10 fig.

44 J. S. WACHER, Excavations at Brought-OnHumber 1958-1961, dans Reports of the Research Committee of the Society of Antiquaries of London, $\mathrm{XXV}, 1969,243$ p., 89 fig. bien cuite. Le col est orné de bandes lissées parallèles ;

39 : vase tourné ; lèvre arrondie; col tronconique ; panse ronde ; couleur brune (10 YR $5 / 1,5 / 2)$; pâte brune à dégraissant sableux, bien cuite. Type IIb des vases tronconiques, connu à Marly, dans le Pas-deCalais à Étaples, à Boulogne $\mathrm{e}^{\mathbf{5}}$, en Picardie à Amiens ;

40 : vase tourné en terra nigra; col tronconique; panse ronde ; couleur noire $(2,5 \mathrm{YR}$ $\mathrm{N} 3 /)$; pâte gris clair, à dégraissant sableux, bien cuite. Le haut de la panse est orné de guillochis très fins groupés par trois. Type proche de ceux connus à La Calotterie ;

41 : vase tourné en terra nigra ; pied saillant, arrondi ; fond creusé ; couleur noire $(2,5$ YR N 3/); pâte gris clair, à dégraissant sableux, bien cuite;

42 : vase tourné ; fond plat; panse oblique ; couleur orange (5 YR $7 / 6$ ); pâte orange à dégraissant sableux, bien cuite.

Les dolia,

43 : dolium tourné; lèvre épaisse, concave, saillante et arrondie à la base; panse ronde; couleur brune (10 YR 4/2, 5/2); pâte brune à dégraissant sableux, bien cuite. La panse est décorée d'incisions ovalaires repoussées. Type connu à Arras (fin $\mathrm{I}^{\mathrm{er}}$, début $\mathrm{II}^{\mathrm{e}} \mathrm{s}$. ) ;

44 : dolium tourné; lèvre épaisse, arrondie ; panse large ; couleur orange (7,5 YR 7/2); pâte orange à dégraissant fait de gravier pilé, bien cuite. La lèvre est ornée de petites incisions rondes. Type connu dans le nord à Maubeuge, en Belgique à Wervik ;

45 : dolium tourné ; lèvre épaisse, arrondie ; col oblique; panse large; couleur orange (5 YR 7/6); pâte orange, à dégraissant sableux, bien cuite. Type proche du précédent;

46 : dolium tourné; lèvre épaisse, arrondie ; couleur grise (10 YR 7/1, 8/1); pâte grise

45 Cl. Seillier, Daniel Haigneré (1824-1893), L'archéologue et son temps, dans Septentrion, 4, 1974, p. 45-60, $15 \mathrm{fig}$. 

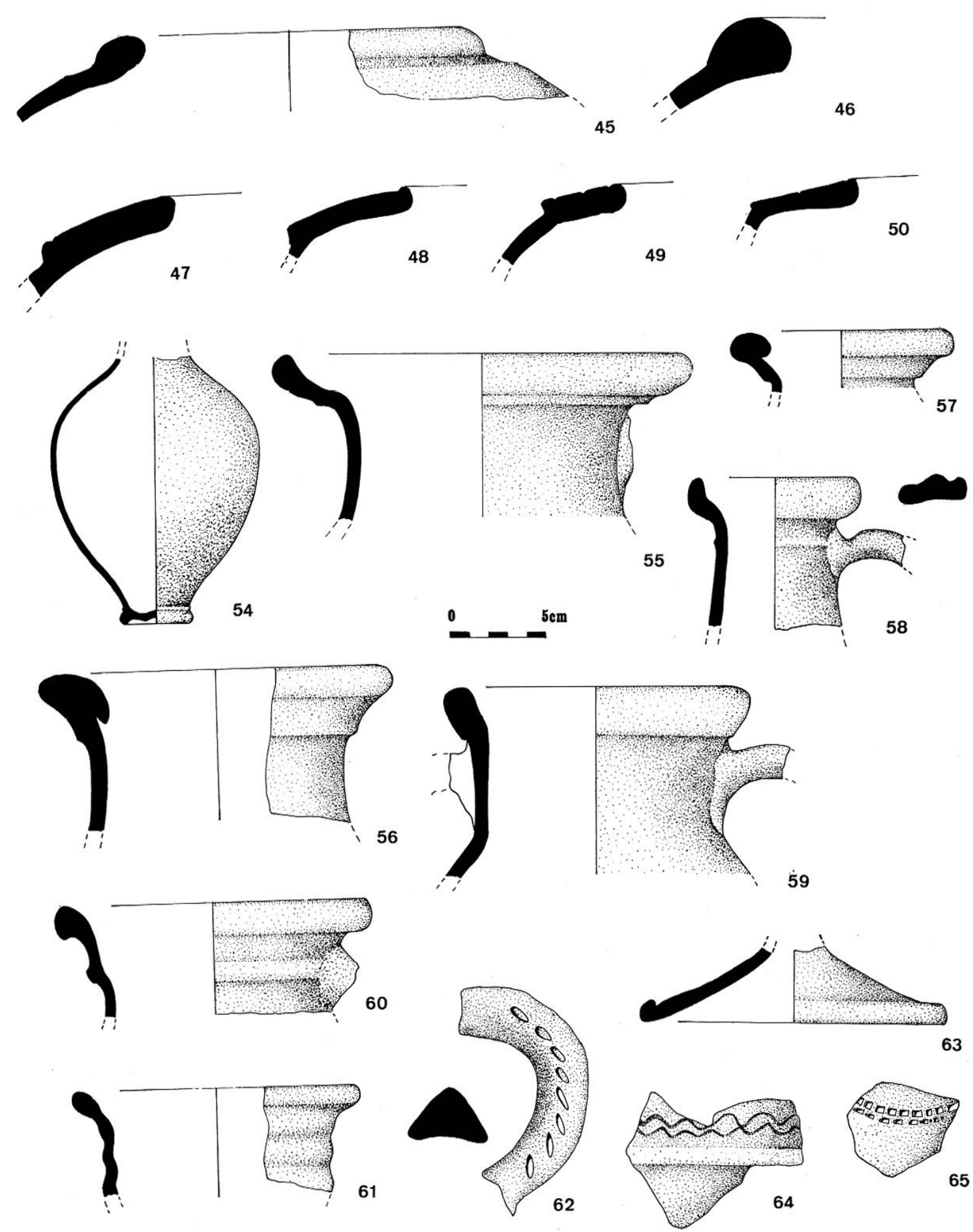

8 Mobilier du four; céramiques communes. 


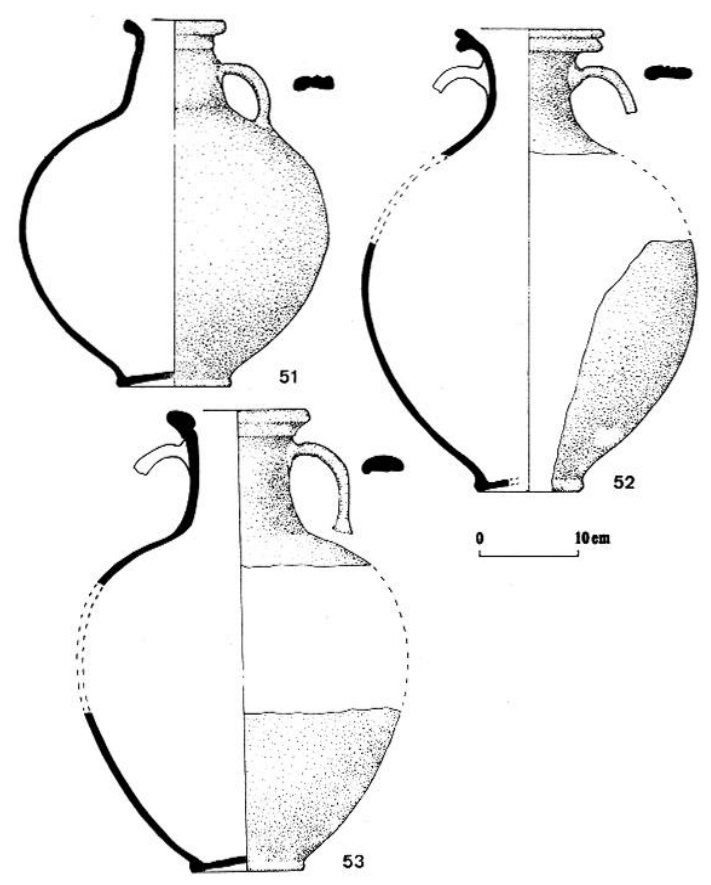

9 Mobilier du four ; céramiques communes.

à dégraissant fait de gravier pilé, bien cuite ;

47 : dolium tourné ; lèvre aplatie, longue, moulurée à la base ; couleur orange (5 YR 7/6); pâte orange à dégraissant fait de gravier pilé, bien cuite. Type connu dans le nord de la France à Maubeuge, Marly (première moitié du II ${ }^{\mathrm{e}} \mathrm{s}$ ), Bourlon (fin du $\mathrm{I}^{\mathrm{er}} \mathrm{s}$., début du ${ }_{\mathrm{II}^{\mathrm{e}}} \mathrm{s}$ ), Lewarde.

48 : dolium tourné ; lèvre longue aplatie, saillante à l'extrémité interne ; couleur orange (5 YR 6/6), pâte orange à dégraissant sableux, bien cuite. Type proche du précédent ;

49 : dolium tourné; lèvre longue, aplatie, moulurée; couleur orange (2,5 YR 6/6); pâte orange à dégraissant sableux bien cuite. Type proche du précédent;

50 : dolium tourné ; lèvre longue, aplatie, moulurée; couleur orange à l'intérieur (5 YR 6/6), beige à l'extérieur (5 YR 7/2); pâte orange à dégraissant sableux, bien cuite. Type proche du précédent.

Les cruches,

51 : cruche tournée ; lèvre ronde; col oblique, moulurée dans sa partie supérieure ; panse large, ronde ; pied arrondi ; fond concave ; anse à deux cannelures, s'attachant sur le col ; couleur orange $(2,5$ YR $6 / 6)$; pâte orange à dégraissant sableux, bien cuite ;

52 : cruche tournée; lèvre à une cannelure; col concave; panse ronde; pied saillant, anguleux ; fond concave; deux anses à trois cannelures, s'attachant sur le col ; couleur orange (5 YR 5/8); pâte orange, à dégraissant sableux, bien cuite. Les cruches à lèvre portant une cannelure sont connues à Bourlon, Alesia ${ }^{46}$, Wervik ;

53 : cruche tournée; lèvre concave repliée vers l'intérieur, col concave; panse ronde; pied oblique; fond concave ; deux anses bombées s'attachant sous la lèvre; couleur orange (5 YR 6/8); pâte orange, à dégraissant sableux, bien cuite;

54 : cruche tournée ; panse ovoïde ; pied oblique, arrondi, mouluré au sommet; fond creusé, marqué d'un anneau circulaire; couleur grise (5 YR 6/1); intérieur rouge (10 R 6/6); pâte rouge, à dégraissant sableux, bien cuite. Type Ia des cruches ovoïdes connu dans le nord à Marly (première moitié du II ${ }^{\mathrm{e}} \mathrm{s}$.), à Famars (II ${ }^{\mathrm{e}} \mathrm{s}$.). Il existe en Belgique à Blicquy, à Montceau-sur-Sambre (fin du ${ }_{{ }^{\prime}} \mathrm{e}$ s. $)^{47}$;

55 : cruche tournée; lèvre arrondie, se terminant en corniche, concave dans sa partie interne; col concave; couleur grise (5 YR $5 / 1)$; traces de peinture blanche; pâte grise à dégraissant sableux, bien cuite;

56 : cruche tournée; lèvre arrondie, concave dans sa partie inférieure, repliée vers l'intérieur ; col concave; couleur orange (2,5 YR 6/8); pâte orange, à dégraissant sableux, bien cuite ;

57 : cruche tournée; lèvre arrondie, concave dans sa partie inférieure, repliée vers l'intérieur; couleur orange (5 YR 6/8); pâte orange à dégraissant sableux, bien cuite ;

46 R. SÉnÉCHAL, Céramique commune d'Alésia. Les cruches, Centre de recherches sur les techniques gréco-romaines, 5, Dijon, 1975, III, 116 fig.

$47 \mathrm{R}$. BRulet, La nécropole gallo-romaine $d u$ Gué d'hameau à Montceau-sur-Sambre, dans Documents et Rapports de la Société Royale d'Archélogie et de Paléontologie de Charleroi, LV, 1970-1971, p. 25-85, 29 fig. 

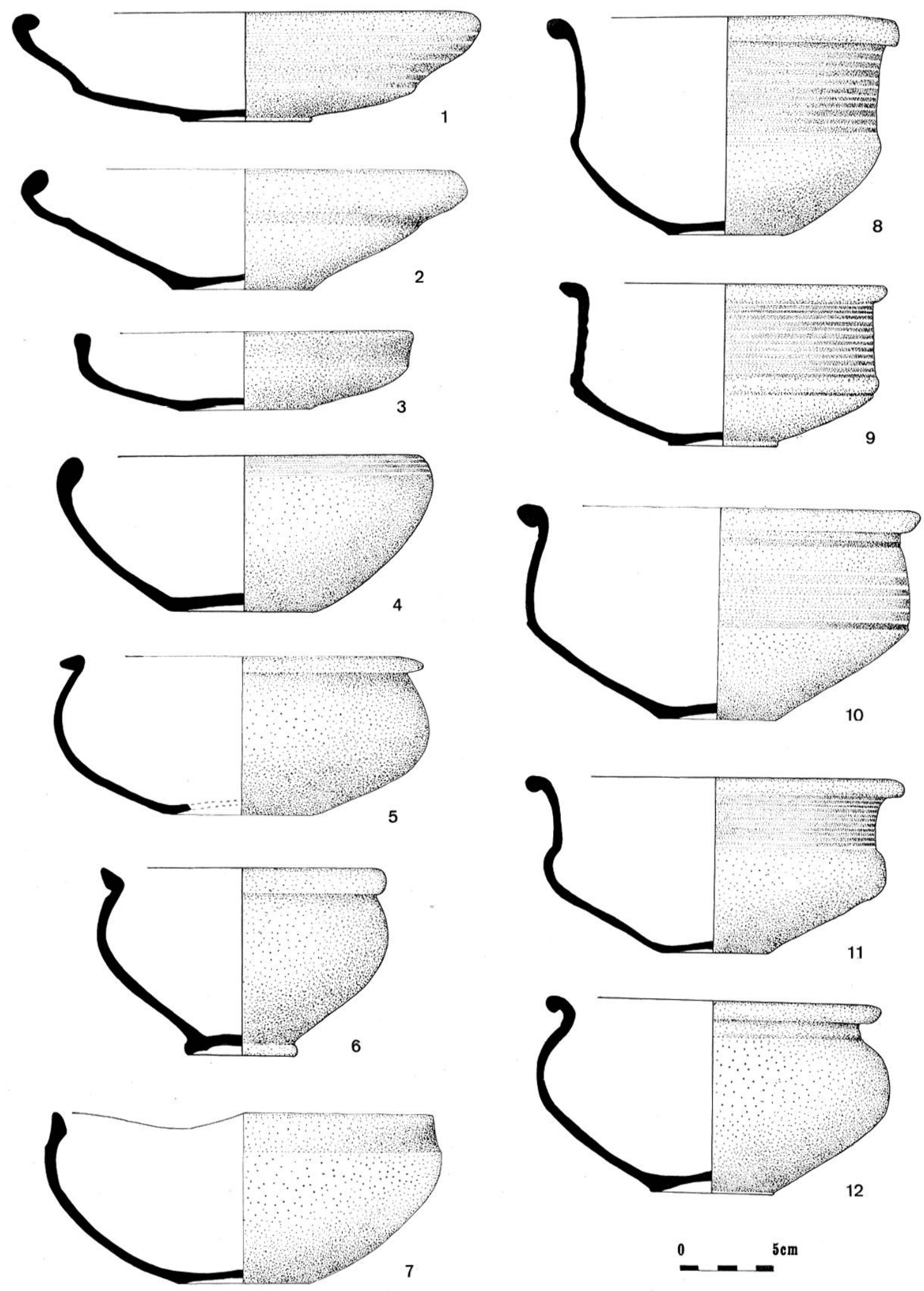

10 Types de céramiques mis au jour en 1971 à Labuissière : assiettes et bols. 

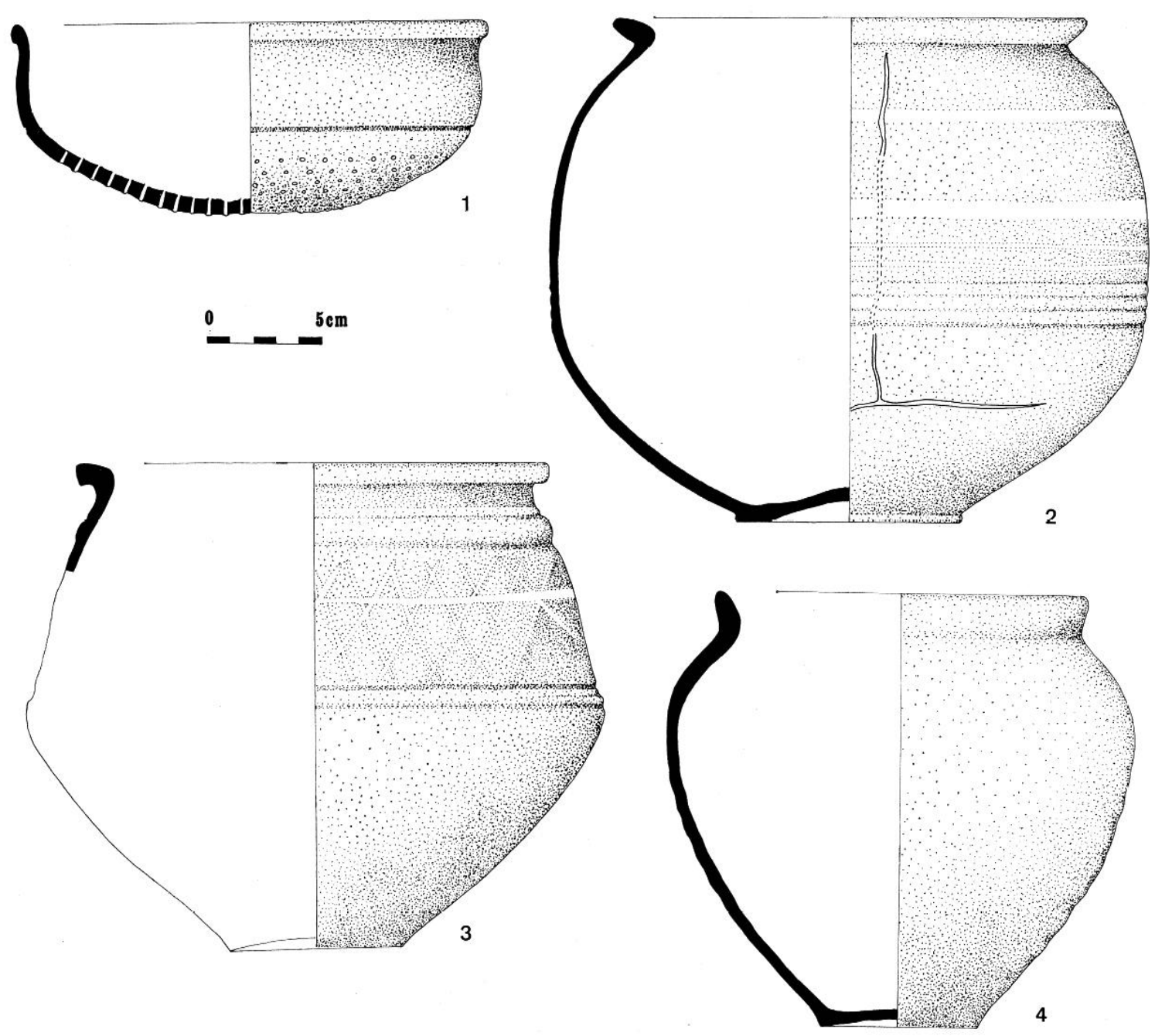

11 Types de céramiques mis au jour en 1971 à Labuissière : marmites et vase.

58 : cruche tournée ; lèvre arrondie ; col oblique mouluré dans sa partie supérieure, anse à deux cannelures; couleur orange (5 YR $6 / 8)$; pâte orange à dégraissant sableux, bien cuite. Type proche de la cruche $\mathrm{n}^{\circ} 51$;

59 : cruche tournée ; lèvre oblique ; col droit; deux anses ; couleur orange (2,5 YR 6/8); pâte orange, à dégraissant sableux, bien cuite ;

60 : cruche tournée; lèvre cannelée; couleur orange (5 YR 6/6); pâte orange à dégraissant sableux, bien cuite ;

61 : cruche tournée; lèvre cannelée ; couleur orange (5 YR 7/6) ; pâte orange à dégraissant sableux, bien cuite ;

62 : anse de cruche tournée; section triangu- laire; couleur orange (5 YR 5/8); pâte orange à dégraissant sableux, bien cuite. L'anse est décorée d'incisions longues, obliques, triangulaires. Type connu à Bourlon.

Les couvercles,

63 : couvercle tourné; base arrondie; partie supérieure oblique; couleur grise (2,5 YR N 5/); pâte grise à dégraissant sableux, bien cuite.

Tessons,

64 : tesson tourné ; couleur orange (5 YR 6/8); pâte orange, à dégraissant sableux bien cuite; décor constitué de deux bandes 


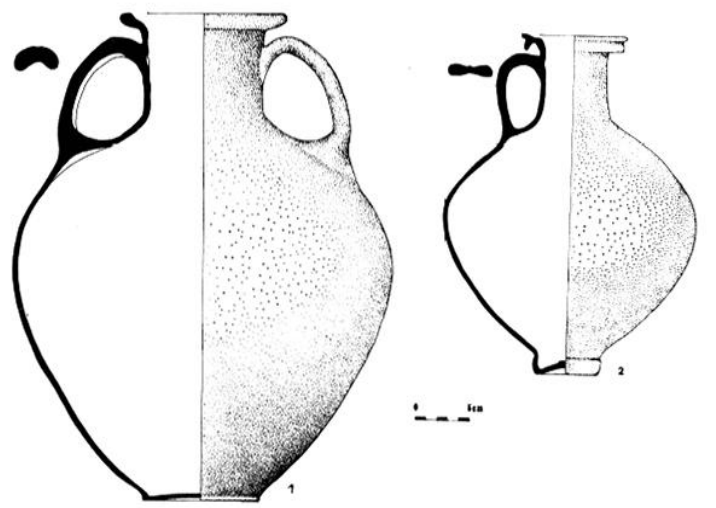

12 Types de céramiques mis au jour en 1971 à Labuissière : cruches.

incisées ondées parallèles. Type connu à Bourlon;

65 : tesson tourné ; couleur grise (7,5 YR N 5/) ; pâte grise à dégraissant sableux, bien cuite; décor de deux séries parallèles de carrés imprimés à la molette. Type connu à Marly.

Les différents types de céramiques. Les céramiques communes trouvées dans ce four sont peu variées. I a production a porté sur des objets d'utilisation courante : bols, marmites, vases, cruches essentiellement. Les types les plus fréquents (fig. 15, 7) sont les bols carénés, les marmites à panse aplatie, les vases tronconiques (fréquence maximale) et les cruches. Les vases appartenant à d'autres catégories (vases à panse ronde, vases ovoïdes) sont très rares et ne font peut-être pas partie de la production de l'officine. Ces formes avaient déjà été reconnues lors des fouilles de 1971 .

Les types de céramiques retrouvés alors sont assez variés. Les assiettes carénées sont nombreuses, ainsi que les assiettes à panse oblique. Les bols ronds et les bols carénés de différents types sont également bien représentés (fig. 10). On note aussi des marmites à panse aplatie (fig. 11). Les vases tronconiques sont très fréquents (fig. 13, 14). Ils présentent de nombreuses variantes. Les bouteilles sont rares, mais les cruches à une ou deux anses sont courantes (fig. 12). Ces céramiques sont décorées d'incisions mais surtout de bandes lissées parallèles ou entrecroisées. Ces objets sont caractéristiques de l'industrie de la céramique de la région du Nord et du Pas-deCalais à cette époque. En effet, les similitudes avec les officines de Bourlon et de La Calotterie sont nombreuses, ce qui laisse supposer une assez grande unité dans la fabrication.

Les différents lypes de lèvres. Les types de lèvres sont souvent étroitement liés aux types de céramiques (fig. 15). Les types les plus fréquents sont les lèvres nos 9 et 11 . Les formes fines sont rares. Certaines lèvres sont spécifiques de types de céramiques comme la lèvre $\mathrm{n}^{0} 16$, uniquement connue sur marmite. D'autres se rencontrent à la fois sur bols carénés, marmites à panse aplatie et vases tronconiques (nos 9, 11, 12). Mais il s'agit ici d'objets pouvant souvent en fait être regroupés en service. Ceci montre que la forme de la lèvre ne dépend pas du hasard mais de la forme de la céramique. Il est ainsi souvent possible d'identifier un type d'objet en possédant uniquement la lèvre.

Les différents lypes de décors. Les décors présents dans le four sont peu variés. Les décors lissés et incisés sont les plus nombreux (nos 1 à 10). Ils sont de types courants, très répandus dans le nord de la France 48 . Les décors plus soignés sont absents, ce qui s'explique par la rareté des céramiques fines. Ici, comme pour les lèvres, ces décors sont étroitement liés aux types de céramique (fig. 15). Les décors lissés se retrouvent sur les bols ronds, carénés, les marmites et vases tronconiques. Les décors incisés sont essentiellement présents sur les vases à panse ronde, les cruches et les dolia. Le décor le plus fréquent est le décor lissé $n^{0} 1$, ce qui est le cas sur la plupart des sites de même époque du Nord et du Pas-de-Calais en raison du grand nombre de bols carénés et de vases tronconiques décorés de cette façon.

Étude chronologique. Une analyse paléomagnétique effectuée sur ce four par le laboratoire de géomagnétisme du Parc Saint-Maur a donné deux datations : $90-95$ et 185 ap. J.-C.

48 M. Tuffreau-LiBre, Les décors sur céramiques communes gallo-romaine dans le Nord de la France (Nord el Picardie), dans Revue archeologique de l'Oise, 1976, p. 21-34, 24 fig. 

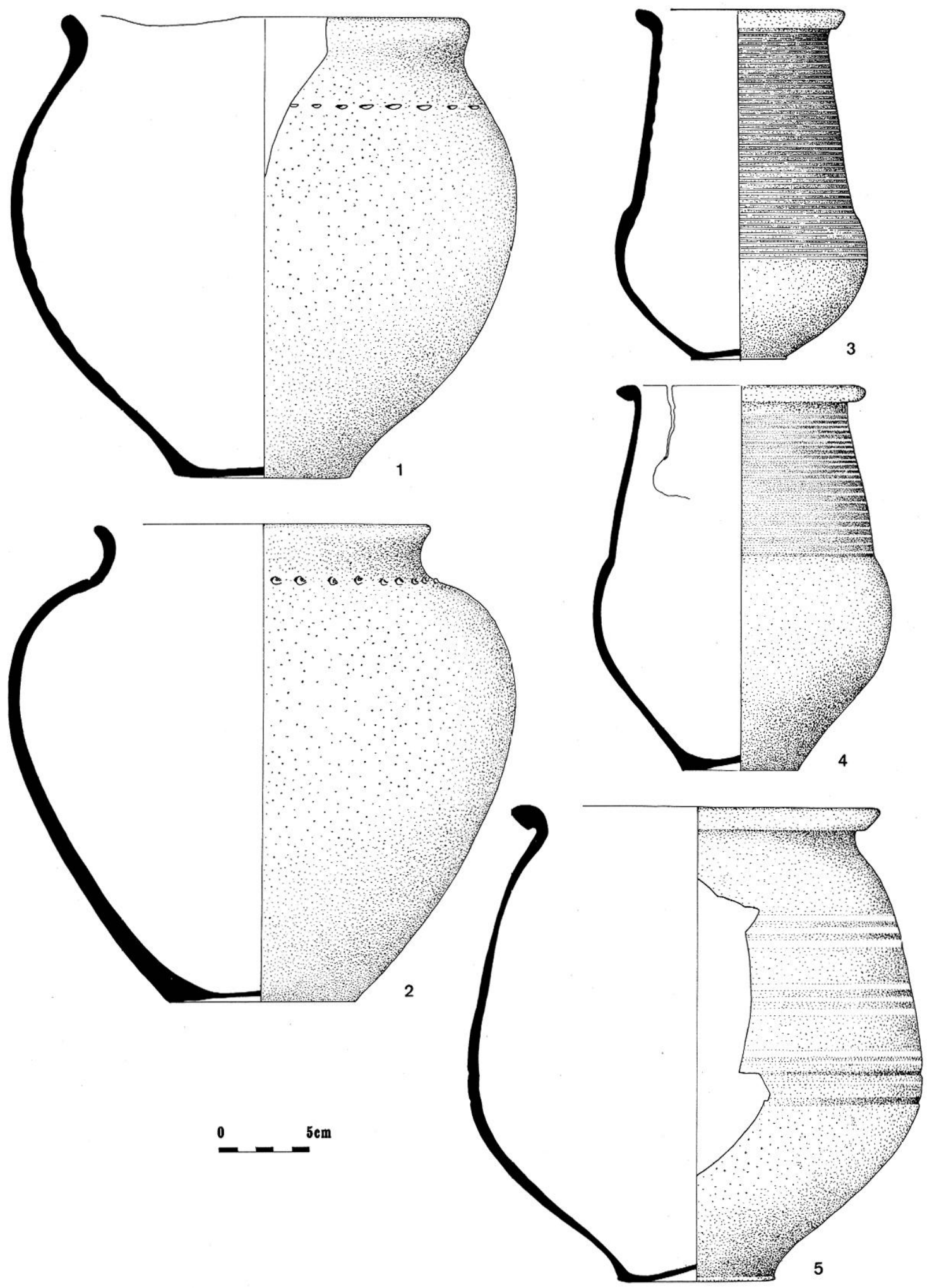

13 Types de céramiques mis au jour en 1971 à Labuissière : vases. 

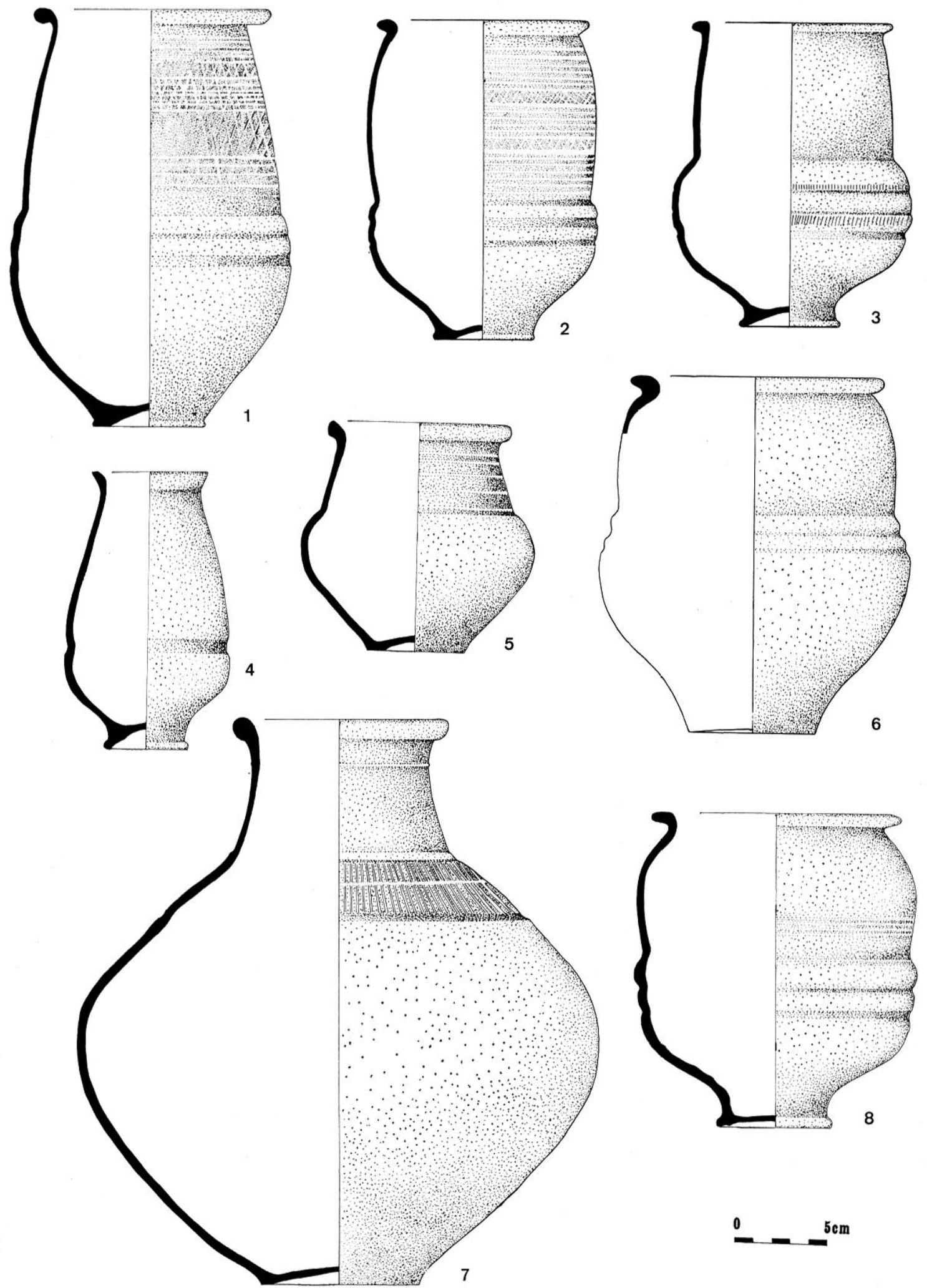

14 Types de céramiques mis au jour en 1971 à Labuissière : vases et bouteille. 

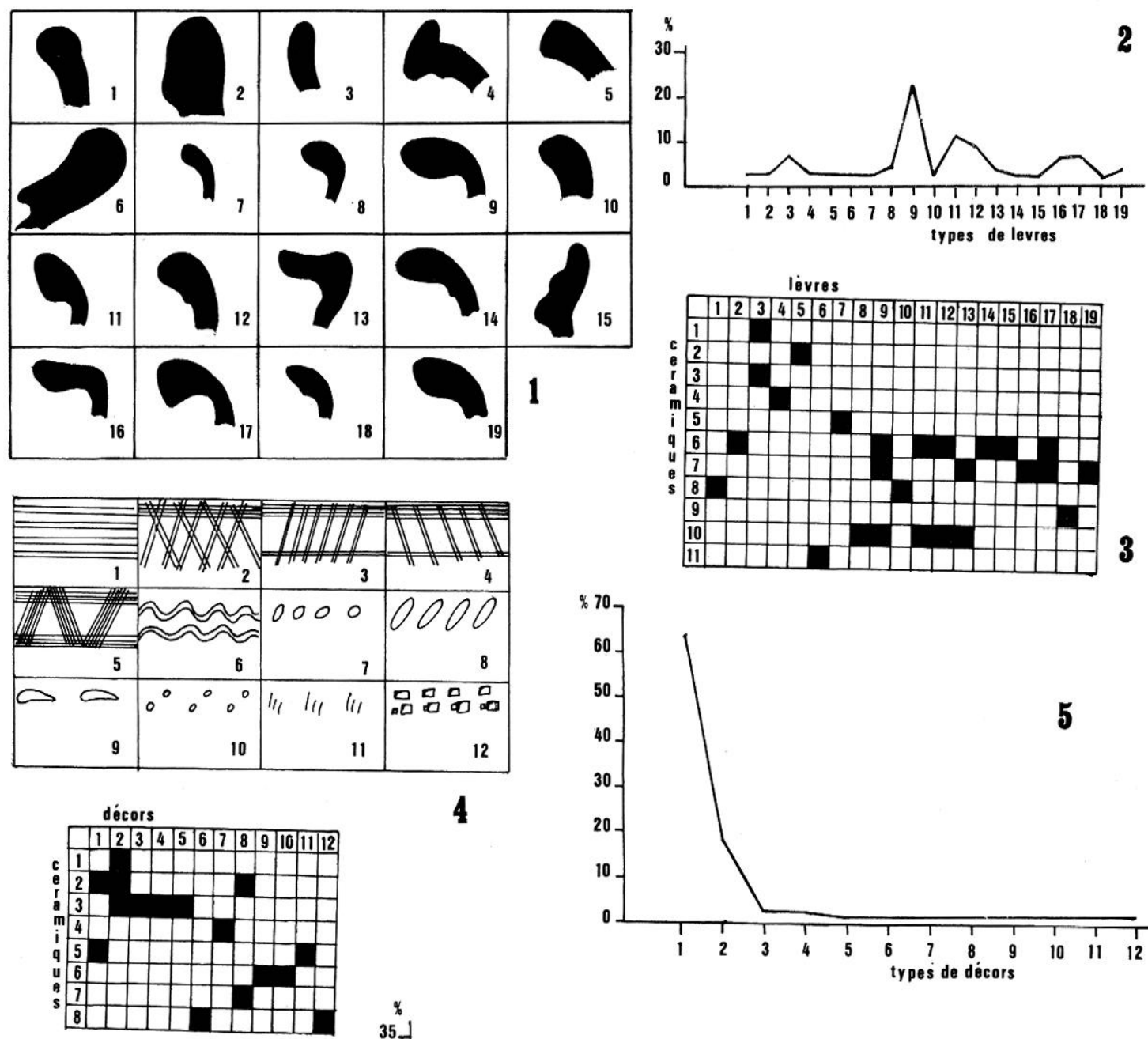

4

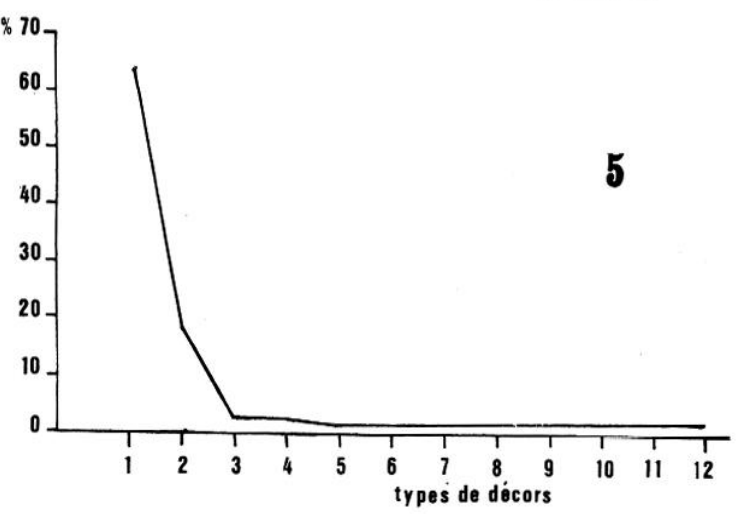

6

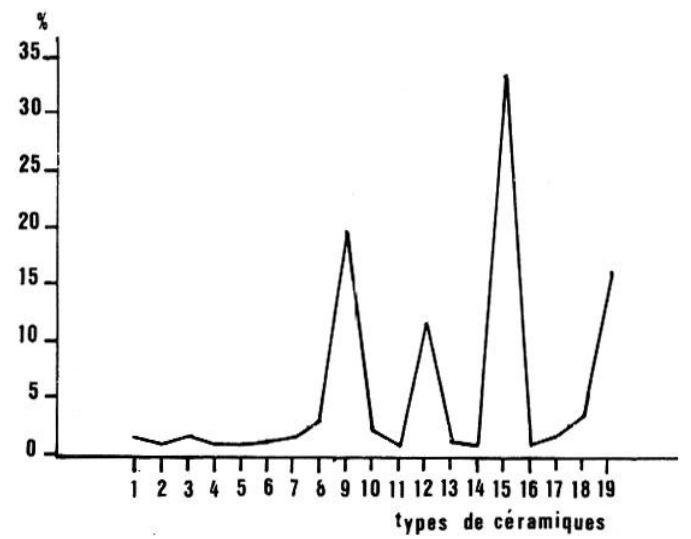

7

$151:$ types de lèvres; $2:$ fréquence des types de lèvres; $3:$ répartition des types de lèvres selon les céramiques (1: assiette à panse ronde, $2:$ assiette carénée, $3:$ assiette à panse oblique, $4:$ assiette à panse anguleuse, $5:$ bol rond, $6:$ bol caréné, $7:$ marmite, $8:$ vase à panse ronde, $9:$ vase ovoĩde, $10:$ vase tronconique, $11:$ dolium) ; $4:$ différents types de décors; 5 : fréquence des différents types de décors; 6 : répartition des types de décors selon les céramiques $(1:$ bol rond, $2:$ bol caréné, $3:$ marmite à panse aplatie, $4:$ vase à pansc ronde, $5:$ vase tronconique, 6 : dolia, $7:$ cruche, $8:$ tesson) ; $7:$ fréquence des différents types de céramiques ( $1:$ assiettes à panse ronde la, $2:$ assiettes carénées IIa, 3 : assiettes à panse oblique IIIa, 4 : assiettes à panse oblique IVa, $5:$ assiettes à panse anguleuse Ia, $6:$ bols carénés VIIIa, $7:$ bols carénés XIVa, $8:$ bols carénés XVIa, $9:$ bols carénés indéterminés, $10:$ mortiers, 11 : marmites à panse oblique Ia, 12 : marmites à panse aplatie $\mathrm{IIa}, 13$ : vases à panse ronde $\mathrm{VIa}, 14$ : vases ovoïdes, 15 : vases tronconiques IIa, 16 : vases tronconiques IIb, $17:$ vases indéterminés, $18:$ dolia, $19:$ cruches). 
L'étude de la céramique fournit des datations beaucoup plus proches de la première que de la seconde. Les comparaisons sont nombreuses avec le site de Marly (première moitić du $\mathrm{II}^{\mathrm{e}} \mathrm{s}$.), avec l'officine de Bourlon (fin du $\mathrm{I}^{\mathrm{er}} \mathrm{s}$., début $\mathrm{du} \mathrm{II}^{\mathrm{e}} \mathrm{s}$.), avec les céramiques les plus anciennes de La Galotterie. Une monnaie du ${ }_{\text {I }}^{\text {er }} \mathrm{s}$. a également été retrouvée. On peut donc situer le remblaiement du four à la fin du ier $\mathrm{s}$. ou au début $\mathrm{du} \mathrm{II}^{\mathrm{e}} \mathrm{s}$. Il faut d'ailleurs souligner que le mobilier n'étant pas forcément celui qui a été fabriqué dans ce four, il peut y avoir un léger décalage dans le temps entre le four et la céramique.

L'intérêt de ce four est donc essentiellement de fournir un ensemble homogène et bien daté de céramiques communes gallo-romaines. Ceci permet de dater plus précisément certains objets identiques découverts en 1971.

Ce mobilier, semblable à celui qui a été découvert dans le Nord et le Pas-de-Calais à la même époque sur des sites divers (officines, villae, dépotoirs), indique une grande unité dans la production. Les mêmes objets ont été fabriqués en même temps dans des endroits très différents comme La Calotterie (Morinie) et Labuissière (Atrébatie). Ceci montre d'ail- leurs, une fois de plus, qu'on ne peut parler de céramique "atrébate». Cette erreur persiste encore, surtout en ce qui concerne le vase tronconique, pourtant connu dans les autres cités avec une fréquence similaire. S'il existe des différences régionales, elles coïncident généralement avec les routes commerciales et non avec les limites des cités. D'autre part, l'étude des types, des lèvres et des décors montre que la production de la céramique obéissait à des normes assez précises. Ces éléments ainsi que l'étendue de l'officine de Labuissière comme de celle de La Calotterie, laissent supposer une fabrication semi-industrielle de la céramique, accompagnée d'un réseau commercial, destiné à diffuser les objets dans la région de production et dans les cités voisines. Il semble que le développement de la fabrication de la céramique commune, commencé dans la deuxième moitié du ier s., a atteint son maximum au ${ }_{{ }_{1}}{ }^{e} s$. pour continuer durant une partie du ${ }_{I_{1}}{ }^{\mathrm{e}} \mathrm{s}$. et ensuite décliner.

Marie Tuffreau-Libre.

$N . R$. - I.es figures 10 à 14 ont été dessinées d'après des originaux de F. Roger et A. Bourgeois. 